\title{
Vascular Cell Adhesion Molecule-1 and the Integrin VLA-4 Mediate Adhesion of Human B Cell Precursors to Cultured Bone Marrow Adherent Cells
}

Daniel H. Ryan, ${ }^{*}$ Bonnie L. Nuccie, ${ }^{*}$ Camille N. Abboud, ${ }^{\star}$ and Jill M. Winslow*

Departments of Pathology and Laboratory Medicine, ${ }^{*}$ and Medicine, ${ }^{\ddagger}$ University of Rochester Medical Center, Rochester, New York, 14642

\begin{abstract}
Adhesion of $B$ cell precursors to accessory cells in the bone marrow microenvironment may be required for normal early $B$ cell development. Human bone marrow $B$ cell precursors adhere more avidly than mature $B$ cells to bone marrow-derived fibroblasts. To determine the mechanism of this adhesion, expression of adhesion proteins on human $B$ precursor cells and cell lines was measured by flow cytometry. The very late antigen (VLA) integrins VLA-4 and VLA-5 were the only adhesion proteins expressed at higher levels in $B$ cell precursors than mature B cells.

Antibodies to the $\alpha$ and $\beta$ chains of VLA-4, but not VLA-5, significantly blocked binding to bone marrow-derived fibroblasts of immature B cells and cell lines. Although fibronectin is a ligand for VLA-4, anti-fibronectin antibody and a soluble fibronectin fragment containing the VLA-4 binding domain did not block adhesion, suggesting that VLA-4 is involved in adhesion of $B$ cell precursors, but not as a fibronectin receptor. Vascular cell adhesion molecule-1 (VCAM-1), the other known counterreceptor for VLA-4, was identified on bone marrowderived fibroblasts, and anti-VCAM-1 significantly blocked adhesion of normal $B$ cell precursors to bone marrow-derived fibroblasts, indicating that VLA-4/VCAM-1 interactions are important in adhesion of $B$ cell precursors to the bone marrow microenvironment. (J. Clin. Invest. 1991. 88:995-1004.) Key words: CD10 • integrins • lymphopoiesis • phorbol esters $\bullet$ pre-B cells
\end{abstract}

\section{Introduction}

The earliest identifiable B lineage precursors are found in the bone marrow. In vitro culture systems that support the proliferation of mouse B cell precursors are dependent on interaction between the $B$ cell precursors and a layer of adherent bone marrow-derived accessory cells (1). Developing B cells lie within membrane infoldings (2) of specific subpopulations of adherent cells (3) and are dependent on contact with these cells for their continued growth (4). This intimate contact between developing B cells and stromal cells is also observed in vivo (5). Adhesion to bone marrow-derived adherent cells is character-

These results were presented in part at the American Society of Hematology Meeting in December 1990 and at the UCLA Symposium "B Cell Development" in April 1990 and published in abstract form (1990. Blood. 76: 218a; 1990. J. Cell. Biochem. 14D: 209).

Address reprint requests to Dr. Ryan, University of Rochester School of Medicine and Dentistry, Box 608, 601 Elmwood Avenue, Rochester, NY 14642.

Received for publication 28 February 1991 and in revised form 1 May 1991.

J. Clin. Invest.

(c) The American Society for Clinical Investigation, Inc. 0021-9738/91/09/0995/10 \$2.00

Volume 88, September 1991, 995-1004 istic of human erythroid (6) and myeloid (7) progenitors, and interaction with adherent cells is required to sustain in vitro myelopoiesis (8). Stromal cells secrete a number of hematopoietic growth factors such as stem cell factor (kit ligand [9]), granulocyte/macrophage colony-stimulating factor, macrophage colony-stimulating factor, and interleukins 6 and 7. Although these factors are capable of affecting hematopoietic precursor cells in the absence of stromal cells, in vivo hematopoiesis and lymphopoiesis are likely to require close contact between progenitors and stroma, since growth factors may rapidly diffuse into the intercellular space or be expressed in a transmembrane form by stroma, as is the case with stem cell factor (9). In vitro culture of normal human B cell precursors remains a challenge (10), but it is likely that stromal cell interactions are important in human B lymphopoiesis as well (11).

Stages in human B cell precursor differentiation can be identified by expression of surface markers such as CD10, CD20, and CD34 (12). We have previously observed that adhesion of normal human $B$ cell precursors to bone marrowderived fibroblasts (BM-FB) ${ }^{1}$ decreases continuously during $B$ cell precursor maturation (13). B cell precursors adhere more avidly to BM-FB than to dermal fibroblasts or other adherent layers (13).

The proteins responsible for adhesion of human or murine $B$ cell progenitors to BM-FB are at present unknown. Monoclonal antibodies to the adhesion protein CD44 (gp90 ${ }^{\text {Hermes}}$ ) block lymphopoiesis in long-term murine bone marrow cultures (14), but do not actually inhibit the adhesion of normal B cell precursors to the adherent cells. Murine B cell precursors bind to fibronectin (15), suggesting a possible role for an integrin fibronectin receptor. However, normal human B cell precursors adhere only weakly to fibronectin (13).

It would be expected that the molecule responsible for adhesion of B cell precursors to BM-FB should be expressed by immature cells and decrease during maturation. However, expression of those adhesion proteins which have been measured on human B cell precursors (LFA-1, CD44, and LECAM1) increases during $B$ cell development (16). Therefore, we investigated the expression and functional activity of additional adhesion proteins on human $B$ cell precursors.

Adhesion receptors are found in at least four protein families (17): integrins; selectins (18), e.g., LECAM1 (Leu 8), LECAM2 (ELAM-1), LECAM3 (GMP-140); cartilage-link proteins, e.g., CD44; and members of the immunoglobulin superfamily, e.g., CD56 (NCAM), CD54 (ICAM-1), vascular cell adhesion molecule-1 (VCAM-1). Integrins consist of noncovalently linked $\alpha$ - and $\beta$ chains and are classified according to their $\beta$ chain into the very late antigen (VLA) integrins $\left(\beta_{1}\right)$, leukocyte integrins $\left(\beta_{2}\right)$, cytoadhesin integrins $\left(\beta_{3}\right)$, and additional molecules expressing $\beta_{4}$ or $\beta_{\mathrm{p}}$ chains. The $\beta_{1}$ integrin

1. Abbreviations used in this paper: BM-FB, bone marrow-derived fibroblasts; FN-40, 40-kD chymopapain fibronectin fragment containing the heparin-binding domain; PE, phycoerythrin; VCAM, vascular cell adhesion molecule; VLA, very late antigen. 
(VLA) subfamily is widely expressed in both hematopoietic and nonhematopoietic cells, and contains seven members, distinguished by association of different $\alpha$ chains with the integrin $\beta_{1}$ chain (19). The hematopoietic expression of some VLA integrins is limited to T cells (VLA-1, -2, -6) or platelets (VLA-2, $-6)$, but VLA-4 and VLA-5 are widely expressed in lymphoid and hematopoietic cells (17). We demonstrate here that normal human B cell precursors express VLA-4 and VLA-5 and bind to BM-FB by means of a VLA-4/VCAM-1 interaction.

\section{Methods}

Cells. Blood and bone marrow samples (posterior iliac crest) were obtained from 20 normal adult volunteer donors with informed consent and light density cells were separated by Ficoll/Hypaque density gradient centrifugation. The 7-29-6 and WIL-2 (20) cell lines were obtained from Dr. Andrew Saxon, University of California, Los Angeles. NALM-6 cells were obtained from Dr. Tucker LeBien, University of Minnesota, and Reh cells from Dr. Jun Minowada, Hayashibara Biochemical Laboratories, Okayama, Japan.

Adherent cells and matrix. Marrow fibroblasts were prepared as previously described (13). Briefly, light density marrow cells were cultured in McCoy's 5A culture medium (Gibco Laboratories, Grand Island, NY) with $10 \%$ fetal calf serum, penicillin, and streptomycin ("culture medium"), and the adherent cells were passaged weekly before seeding into Falcon 24-well plates (Becton-Dickinson, Lincoln Park, NJ) at least $1 \mathrm{wk}$ before each binding experiment. Skin fibroblasts were prepared from human foreskin fibroblasts passaged in a similar fashion. Fibronectin and collagen-coated wells were prepared as described (13) by incubating wells with $20 \mu \mathrm{g} / \mathrm{ml}$ of plasma fibronectin or collagen (Collaborative Research, Bedford, MA) for $60 \mathrm{~min}$ at room temperature, and washing twice with phosphate-buffered saline (PBS).

Antibodies and reagents. Phorbol 12-myristate 13-acetate (PMA) was purchased from Sigma Chemical Co., St. Louis, MO. Antibodies and additional reagents were obtained from Becton-Dickinson Immunocytometry Systems, San Jose, CA (CD56 [NCAM; Leu 19], antiLECAM1 [Leu-8 phycoerythrin $\{$ PE $\}$ conjugate], CD11c [p150,95 $\alpha$ chain], avidin PE), Coulter Immunology, Hialeah, FL (CD29 [VLA $\beta_{1}$ chain], CD1 1b [Mo1 FITC], CD20 FITC, CD10 PE, and FITC-conjugated mouse isotype controls for IgG1, IgG2a, IgG2b, and IgM), Fisher Scientific Co., Orangeburg, NJ (FITC-conjugated isotype-specific goat anti-mouse IgG1, IgG3, and IgG2b), Telios Pharmaceuticals, San Diego, CA (CD49b [VLA-2 $\alpha$ chain], CD49c [VLA-3 $\alpha$ chain], CD49e [VLA-5 $\alpha$ chain], GRGDSP, GRGESP, and a 40-kD chymopapain fibronectin fragment containing the heparin-binding domain [FN40]), AMAC, Inc., Westbrook, ME (CD49d [VLA-4 $\alpha$ chain], CD18 [LFA-1 $\beta$ chain], CD41a [gpIIb/IIIa], CD61 [integrin $\beta_{3}$ chain], CD54 [ICAM-1]), Chemicon International, Inc., El Segundo, CA (polyclonal rabbit anti-fibronectin, anti-collagen I and IV [used as a mixture]), Dako Corp., Carpinteria, CA (CD1 1a [LFA-1 $\alpha$ chain], FITC-conjugated $\mathrm{F}(\mathrm{ab})_{2}$ goat anti-mouse Ig), and Supertechs, Bethesda, MD (rabbit anti-terminal deoxynucleotidyl transferase used as a control for polyclonal rabbit antibodies). The blocking CD49e antibody BIIG2 was a gift of Dr. Carolyn Damsky, University of California, San Francisco (21), CD44 antibody was a gift of Dr. Geoffrey Kansas, University of Iowa (16), and anti-VCAM-1 (E1/6) was a gift of Dr. Michael Bevilacqua, Brigham and Women's Hospital (22). All antibodies were of the mouse IgG1 isotype except for CD10 (IgG2a), CD20 (IgG2a), CD11b (IgM), CD11c (IgG2b), BIIG2 (rat IgG), and the polyclonal antisera.

Adhesion protein expression. For phenotyping of adhesion proteins, bone marrow cells were stained with an adhesion marker vs. CD10 to identify the strongly CD10-positive $\left(\mathrm{CD} 10^{\mathrm{hi}}\right)$ early B cell precursors and weakly $\mathrm{CD} 10$-positive $\left(\mathrm{CD} 10^{10}\right)$ late B cell precursors (12). Cells were stained as described (12), incubating first with CD10 PE and unconjugated antibody, followed by FITC-conjugated goat anti-mouse Ig specific for the isotype of the unconjugated antibody used. Blood mononuclear cells were stained with $\mathrm{CD} 20$ biotin plus unconjugated adhe- sion protein antibody followed by avidin PE plus FITC-conjugated goat anti-mouse Ig specific for the isotype of the unconjugated antibody used. Two antibodies were available as direct fluorochrome conjugates: CD1 lb FITC and Leu 8 PE. These antibodies were used in a single incubation step with CD10 PE or CD20 PE (for CD11b FITC), or with CD10 FITC or CD20 FITC (for Leu 8 PE) to stain bone marrow or blood, respectively. Cell lines were stained with antibody to the adhesion protein, followed by FITC-conjugated goat antimouse Ig.

After staining, fresh cells were held overnight at $4^{\circ} \mathrm{C}$ in medium before flow cytometry analysis. In the case of Leu 8 (but none of the other antibodies used), fluorescence decreased after overnight storage, possibly due to shedding of antigen (23). Therefore, for Leu 8 analysis, cells were stained and analyzed on the same day.

Stained cells were analyzed on a flow cytometer (EPICS C, Coulter Corp.) using standard light scatter gates for mononuclear cells (12) to obtain a two parameter histogram of log green fluorescence (FITC) vs. $\log$ red fluorescence (PE). For determination of adhesion protein expression of bone marrow cells, the mean log green fluorescence channel of the CD10 $0^{\text {hi }}$ cells (red fluorescence channel $>42$ ) was determined separately from the $\mathrm{CD} 10^{10}$ cells (red fluorescence channels 26-41). For peripheral blood cells, the mean $\log$ green fluorescence channel of all CD20-positive cells was determined. The mean log green fluorescence channel of the cell lines was determined directly from a single parameter histogram.

The mean log fluorescence channel was converted to linear equivalents as previously described (12). A mixture of four preparations of microspheres (Quantitative Microbead Standards, Flow Cytometry Standards Corp., Research Triangle Park, NC), each conjugated with a specific number of fluorescein molecules, was run with each experiment at the same flow cytometer settings to generate a linear regression (fluorescein molecules vs. linear fluorescence intensity) for quantitation of fluorescence measurements. The linearity of the fluorescence measurements was reflected by the high correlation coefficient (average of $0.9979 \pm 0.0003 ; n=16$ ) of fluorescence measurements from the four microsphere populations relative to their fluorescein content. In order to determine the fluorescence intensity specifically due to the adhesion protein antibody, the mean fluorescence intensity of cells stained with isotype specific control antibody was subtracted from that of cells stained with the adhesion protein antibody to obtain the final fluorescence intensity measurement.

Binding assay. Binding experiments were performed as previously described (13) with minor modifications. Briefly, $10^{6}$ light density marrow or blood cells in $100 \mu \mathrm{l}$ of culture medium were added to previously prepared adherent cells or matrix in 24-well plates containing $200 \mu \mathrm{l}$ of culture medium. After a 2 -h incubation at $37^{\circ} \mathrm{C}$, nonadherent cells were removed by four washes with culture medium. After these washes, adherent marrow cells were removed by two forceful washes with medium, which did not disturb the fibroblast layer. Viable cell counts of the starting cell suspension and the adherent marrow cells were performed on a hemocytometer using propidium iodide. Cells were stained in one step with CD20 FITC and CD10 PE and analyzed on an EPICS $\mathrm{C}$ flow cytometer to enumerate $\mathrm{CD} 10^{+} / \mathrm{CD}^{-} 0^{-}, \mathrm{CD}^{+} 0^{+} /$ $\mathrm{CD}^{+} 0^{+}$, and $\mathrm{CD} 10^{-} / \mathrm{CD} 20^{+}$cells as previously described (13). Each experiment was performed in triplicate wells, which were incubated, counted, stained, and analyzed separately. The percent adherent cells in each B lineage subpopulation was calculated as described (13). Briefly, the absolute number of each $B$ cell subpopulation added to the well at the beginning of the adhesion assay was determined by multiplying the total number of bone marrow cells added to the well by the percent positive cells in that $B$ cell subpopulation as determined by flow cytometry. In a similar fashion, the absolute number of each $B$ cell subpopulation recovered in the adherent fraction was determined by multiplying the total number of adherent bone marrow cells by the percent positive cells in that $B$ cell subpopulation as determined by flow cytometry. The percent adherent cells in a B cell subpopulation is based on the ratio of the absolute number of cells recovered in the adherent fraction divided by the absolute number of cells in that subpopulation added to the well. 
In experiments with PMA, PMA in ethanol was added in a final concentration of $1.6 \mathrm{nM}$ (final ethanol concentration $0.1 \%$ ) to the incubation mixture after $1.5 \mathrm{~h}$ of incubation. This concentration and time course was shown to be most effective in enhancing adhesion of bone marrow B lineage cells by dose-response and time course experiments. The controls for these experiments (treated with $0.1 \%$ ethanol alone) showed similar results to controls without ethanol.

Blocking studies. $10^{6}$ light density marrow or blood cells in $100 \mu \mathrm{l}$ of culture medium were incubated with $0.9 \mu \mathrm{g}$ of blocking antibody (1:2 dilution for BIIG2 culture supernatant) or isotype matched irrelevant antibody and incubated for $30 \mathrm{~min}$ at $23^{\circ} \mathrm{C}$ before adding to previously prepared adherent cells or matrix in 24-well plates, making up a final volume of $300 \mu \mathrm{l}$ per well (final antibody concentration of $3 \mu \mathrm{g} / \mathrm{ml}$ ). The peptides GRGDSP and GRGESP(identified by the standard single-letter designation for amino acids) were used at $1 \mathrm{mM}$, and FN-40 at $100 \mu \mathrm{g} / \mathrm{ml}$ final concentration. The cells were then incubated and washed as described above. To block adhesion using antibodies to components of the adherent layer (i.e., fibronectin, collagen, CD54, VCAM-1), the appropriate antibody ( $3 \mu \mathrm{g} / \mathrm{ml}$ for CD 54 ; undiluted culture supernatant for anti-VCAM-1 [dialyzed against culture medium to remove azide]; 1:40 dilution for polyclonal antibodies) was incubated with the adherent layer for $30 \mathrm{~min}$ at $23^{\circ} \mathrm{C}$ before addition of the cells.

In experiments designed to block PMA-induced adhesion, blocking reagents were added as described above, and PMA was added to the wells containing cells and adherent layer after $1.5 \mathrm{~h}$ of incubation (in the continuing presence of antibody).

Fluorescence staining of BM-FB. For phenotypic analysis of BMFB, trypsinized BM-FB were seeded into eight-well slide chambers (Nunc, Inc. Naperville, IL) instead of 24-well plates, and allowed to reach confluency. Adherent cells were incubated in situ with antiVCAM-1 (1:2 dilution of culture supernatant), anti-CD49d, anti$\mathrm{CD} 54$, anti-fibronectin, or control antibody for $30 \mathrm{~min}$ at $23^{\circ} \mathrm{C}$, then washed thrice with culture medium, incubated with FITC-conjugated goat anti-mouse Ig, then washed again. After the last wash, the culture chambers were removed from the slide, the cells were fixed in $2 \%$ paraformaldehyde, and a coverslip was placed over the stained cells for fluorescence microscopy analysis.

\section{Results}

Adhesion of $B$ precursor cell lines to $B M-F B$ and matrix components. The adhesion of four B lineage cell lines was compared to that of the corresponding normal B lineage cells in the bone marrow. The leukemic cell lines NALM-6 and Reh are $\mathrm{CD}^{+}{ }^{+} /$ $\mathrm{CD}^{+} 0^{+} / \mathrm{TdT}^{+} /$surface $\mathrm{Ig}^{-}$, a B cell precursor phenotype. The transformed $B$ cell lines 7-29-6 and WIL-2 are CD19+ ${ }^{+} / \mathrm{CD}^{-} /$ $\mathrm{TdT}^{-} /$surface $\mathrm{Ig}^{+}$, a mature B cell phenotype. As is shown in Fig. 1, the two precursor cell lines showed significantly higher adhesion to BM-FB than to dermal FB, whereas two mature $B$ cell lines were much less adherent to the BM-FB and did not show significantly higher binding to BM-FB than to dermal FB. NALM-6 bound less well to fibronectin (adhesion 27 $\pm 5 \% ; n$ $=7)$, collagen $(6 \pm 3.0 \% ; n=5)$, or laminin $(0.1 \pm 0.1 \% ; n=3)$ than to BM-FB $(41 \pm 8 \% ; n=7)$.

Expression of adhesion proteins by $B$ lineage cells. In order to determine which molecules might be responsible for the adhesion of $\mathrm{B}$ lineage precursors to BM-FB, the expression of adhesion-related surface molecules on normal $B$ lineage cells and cell lines was determined using two-color immunofluorescence as shown in Fig. 2. The fluorescence intensity in FITC equivalents for normal marrow B lineage cells is shown in Fig. 3. The only adhesion molecules to be expressed at significantly higher levels in B cell precursors than mature B cells were the VLA-4 and VLA-5 $\alpha$ chains (CD49d and CD49e) and the com-

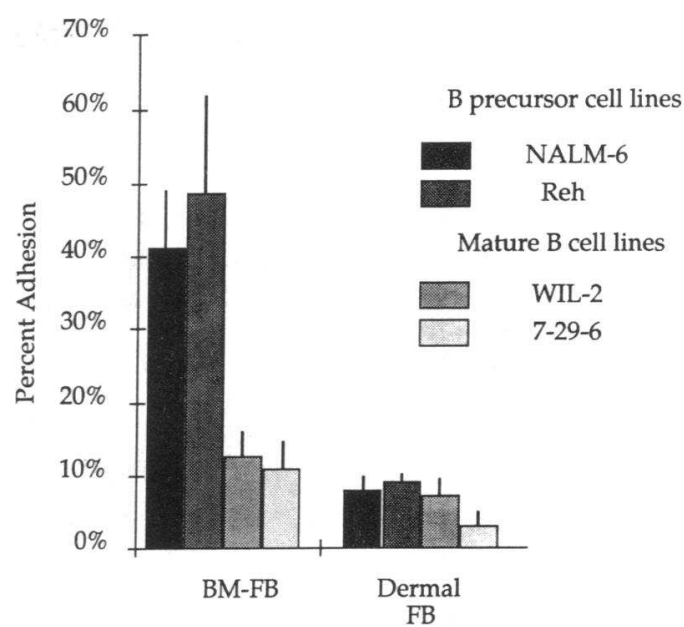

Figure 1. Adhesion of B cell lines to BM-FB and dermal fibroblasts. The percent adherent cells (mean \pm SEM) is shown for each cell line $(n=3$, each experiment performed in triplicate). The adhesion to BM-FB of the two immature B cell lines is statistically higher $(P$ $<0.05$ ) than that of the two mature $B$ cell lines. There is no significant difference in adhesion of the two mature cell lines to BM-FB or dermal fibroblasts, although the two immature cell lines adhere significantly $(P<0.05)$ better to BM-FB than to dermal fibroblasts.

mon VLA $\beta$ chain (CD29). In contrast, expression of several other adhesion molecules (CD11a, CD18, CD41a, CD61, CD44, Leu 8, and CD54) increased with differentiation.

Cell lines generally showed higher quantitative expression of adhesion proteins than their normal counterparts (Fig. 4), but the pattern was qualitatively similar to that found on normal marrow B lineage cells. Immature B cell lines (NALM-6 and Reh) expressed only VLA-4 and VLA-5, whereas mature B cell lines (WIL-2, 7-29-6, Daudi) lacked VLA-5, and expressed lower levels of VLA-4, but were positive for CD11a, CD18, CD44, CD61, and CD54.

Inhibition of adhesion by blocking antibodies and peptides. In order to determine which of the expressed adhesion proteins was actually responsible for adhesion to BM-FB and fibronectin in our in vitro model, inhibition studies with blocking antibodies and peptides were performed.

Each of the adhesion receptor antibodies or reagents used in the inhibition experiments blocks adhesion at the concentration used. Aggregation and adhesion of phorbol treated 7-29-6 cells to BM-FB, which is largely dependent on LFA-1/ICAM-1 interaction, was blocked by CD18 (83\%) and CD54 (59\%) antibodies. Binding of NALM- 6 cells to fibronectin was inhibited by $84 \%( \pm 13 \% ; n=.3)$ by anti-fibronectin antibody. Binding of NALM-6 cells to collagen I was $90 \%(n=2)$ inhibited by the mixture of anti-collagen I and IV antibodies used in these experiments. CD29 and CD49d antibodies inhibited adhesion of normal B cell precursors and cell lines as described below. GRGDS was used at an inhibitory concentration (1 mM). The CD49e antibody used (BIIG2) was used at a concentration demonstrated to show blocking of VLA-5 dependent adhesion (21). FN-40 was used at a concentration $(100 \mu \mathrm{g} / \mathrm{ml})$ shown to inhibit binding of VLA-4-positive cells to FN-40-coated plates by $90 \%$ (24). Anti-VCAM-1 antibody E1/6 culture supernatant inhibits adhesion of lymphocytes to IL-1-treated endothelial cells (25), and was also inhibitory in the present study.

The effect of blocking antibodies on adhesion of normal 


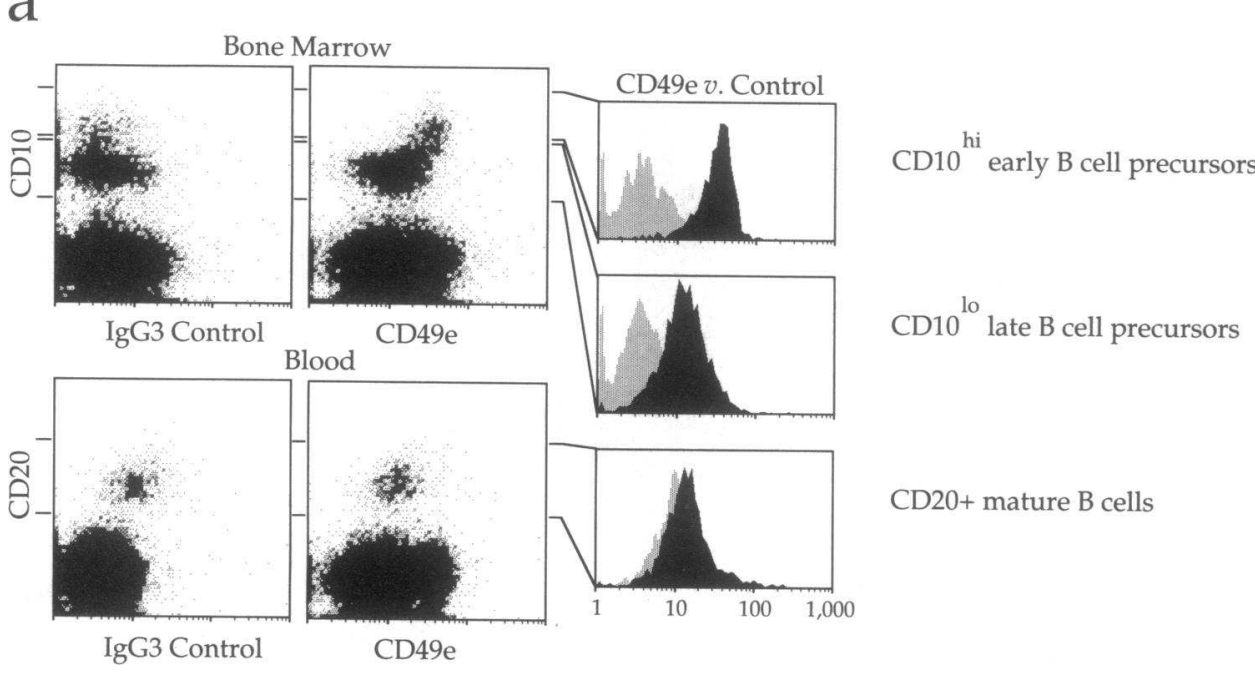

$\mathrm{b}$

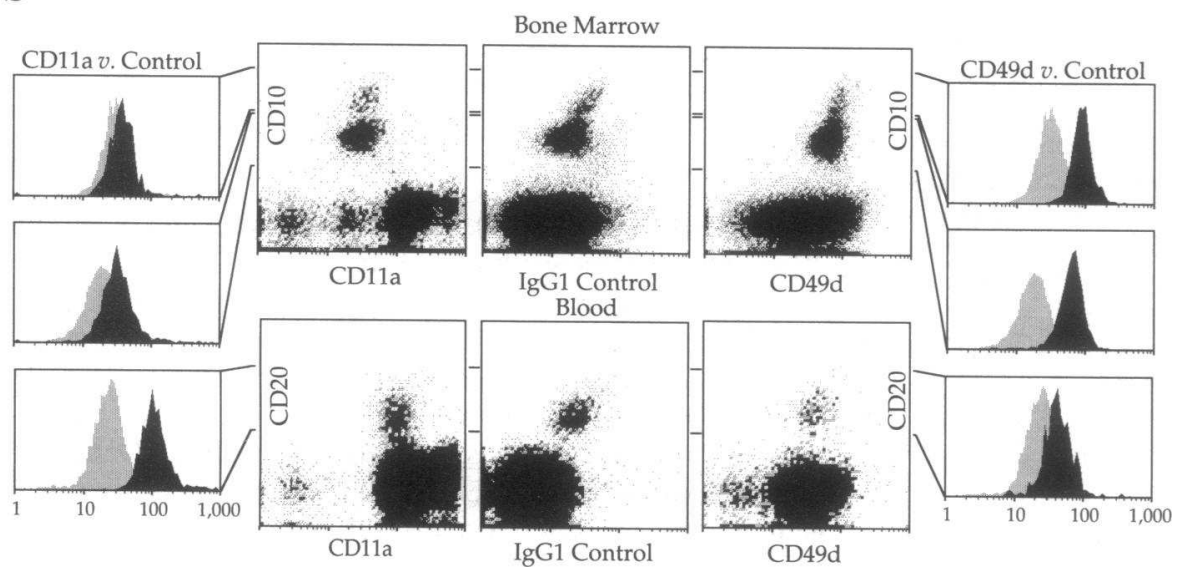

Figure 2. Fluorescence histograms of adhesion protein expression by normal B lineage cells. (a) CD49e (VLA-5 $\alpha$ chain). Two-parameter histograms of green vs. red fluorescence (based on cells within "lymphoid" light scatter gates) of light density bone marrow cells stained with IgG3 control vs. CD10 (upper left) or CD49e vs. CD10 (upper center) and blood mononuclear cells stained with IgG3 control vs. CD20 (lower left) or CD49e vs. CD20 (lower center) are shown. The bone marrow contained $13.4 \% \mathrm{CD}^{+}{ }^{+}$ cells in the "lymphoid" scatter gates, of which $16 \%$ showed high CD10 expression, similar to previously published data (12). CD49e expression on the CD10 $0^{\text {hi }}$ early $B$ cell precursors was determined by analysis of a single-parameter green fluorescence histogram containing only cells with high CD10 expression (falling within the upper pair of horizontal lines intersecting the two parameter histograms). This histogram is shown at upper right, with the fluorescence of CD49e stained cells in black and IgG3 stained cells in gray. The fluorescence scale is logarithmic, with a range of fluorescence intensity of 1-1,000 (shown at the bottom of each histogram). The specific fluorescence due to CD49e expression was calculated as the difference between the mean fluorescence of cells stained with CD49e and cells stained with IgG3 control. This arbitrary scale of fluorescence inten-

sity was converted to FITC equivalents as described in Methods by comparison with microspheres containing measured numbers of FITC molecules. In a similar fashion, expression of $\mathrm{CD} 49 \mathrm{e}$ on the $\mathrm{CD} 10^{\text {to }}$ late marrow B cell precursors (cells falling within the middle pair of horizontal lines) is shown at center right, and expression of $\mathrm{CD} 49 \mathrm{e}$ on the $\mathrm{CD} 20^{+}$blood B cells (cells falling within the lower pair of horizontal lines) is shown at lower right. The differing amounts of green fluorescence of $\mathrm{CD} 10^{+}$and $\mathrm{CD} 20^{+}$cells stained with control antibody is due to a small amount of cross-reactivity of the secondary IgG3 specific goat anti-mouse antibody with the CD20 antibody, but not the CD10 (both IgG2a). CD49e expression of $\mathrm{CD} 10^{\mathrm{hi}}$ cells in this sample was 10,100 , of $\mathrm{CD} 10^{\mathrm{to}}$ cells was 2,500 , and of $\mathrm{CD} 20^{+}$cells was 1,400 FITC equivalents. $(b)$ CD11a (LFA-1 $\alpha$ chain) and CD49d (VLA-4 $\alpha$ chain). Fluorescence analysis is as described above in $a$. In the center are six two-parameter fluorescence histograms: bone marrow light density cells stained with CD11a vs. CD10 (upper left), IgG1 control vs. CD10 (upper center) or CD49d vs. CD10 (upper right), and blood mononuclear cells stained with CD1 la vs. CD20 (lower left), IgG1 control vs. CD20 (lower center) or CD49d vs. CD20 (lower right). Analysis of CD1 1a expression is based as in $a$ on single-parameter green fluorescence histograms containing only CD10 $0^{\text {hi }}$ cells ( far left-upper), CD10 $0^{10}$ cells ( far left-center), or CD20 cells ( far left-lower). The fluorescence of CD1 la-stained cells is shown in black and IgG1 stained cells in gray. CD1 la expression of CD10 $10^{\text {hi }}$ cells in this sample was 1,700 , of CD10 $0^{\text {to }}$ cells was 5,100 , and of CD20 cells was 39,600 FITC equivalents. Analysis of CD49d expression is based on histograms containing only CD10 ${ }^{\text {hi }}$ cells (far right-upper), CD10 ${ }^{\text {to }}$ cells ( far right-center), or $\mathrm{CD} 20^{+}$cells ( far right-lower). The fluorescence of CD49d stained cells is shown in black and IgG1-stained cells in gray. CD49d expression of $C D 10^{\text {hi }}$ cells in this sample was 24,300 , of $C D 10^{10}$ cells was 17,400 , and of CD20 $0^{+}$cells was 8,400 FITC equivalents.

marrow B lineage cells to BM-FB is summarized in Fig. 5. The results for the two normal $B$ cell precursor subpopulations $\mathrm{CD} 10^{+} / \mathrm{CD} 20^{-}$and $\mathrm{CD} 10^{+} / \mathrm{CD} 20^{+}$cells were similar, but markedly different from the mature $\mathrm{CD} 10^{-} / \mathrm{CD} 20^{+} \mathrm{B}$ cells. Binding of normal $\mathrm{CD} 10^{+}$cells to BM-FB was significantly inhibited by CD49d, CD29d, and anti-VCAM-1 but not by CD49e, GRGDSP, CD18, anti-fibronectin, or anti-collagen antibodies. Binding of $\mathrm{CD}^{+} 0^{+}$cells to $\mathrm{BM}-\mathrm{FB}$ was also not inhibited by anti-CD54 or soluble FN-40 (data not shown).
The same degree of inhibition was observed using antiVCAM- 1 or antibodies to the $\alpha$ or $\beta$ chains of VLA-4 (CD49d or CD29). Incubation with 1,3 , and $10 \mu \mathrm{g} / \mathrm{ml}$ of anti-CD49d caused a similar degree of blocking (data not shown), indicating that the concentration used in these experiments $(3 \mu \mathrm{g} / \mathrm{ml})$ was saturating with respect to inhibition of adhesion. Binding of $\mathrm{CD}^{-} 0^{-} / \mathrm{CD}^{+} 0^{+}$mature $\mathrm{B}$ cells to $\mathrm{BM}-\mathrm{FB}$ was quantitatively lower than either $\mathrm{CD}_{10}{ }^{+}$subset, and was not significantly inhibited by any of the antibodies or peptides used. 


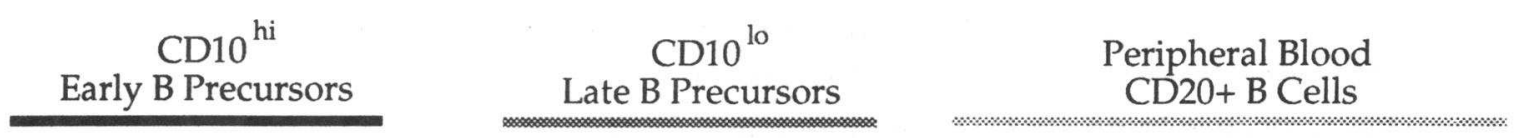

Mean Fluorescence Intensity (FITC equivalents x 1,000)

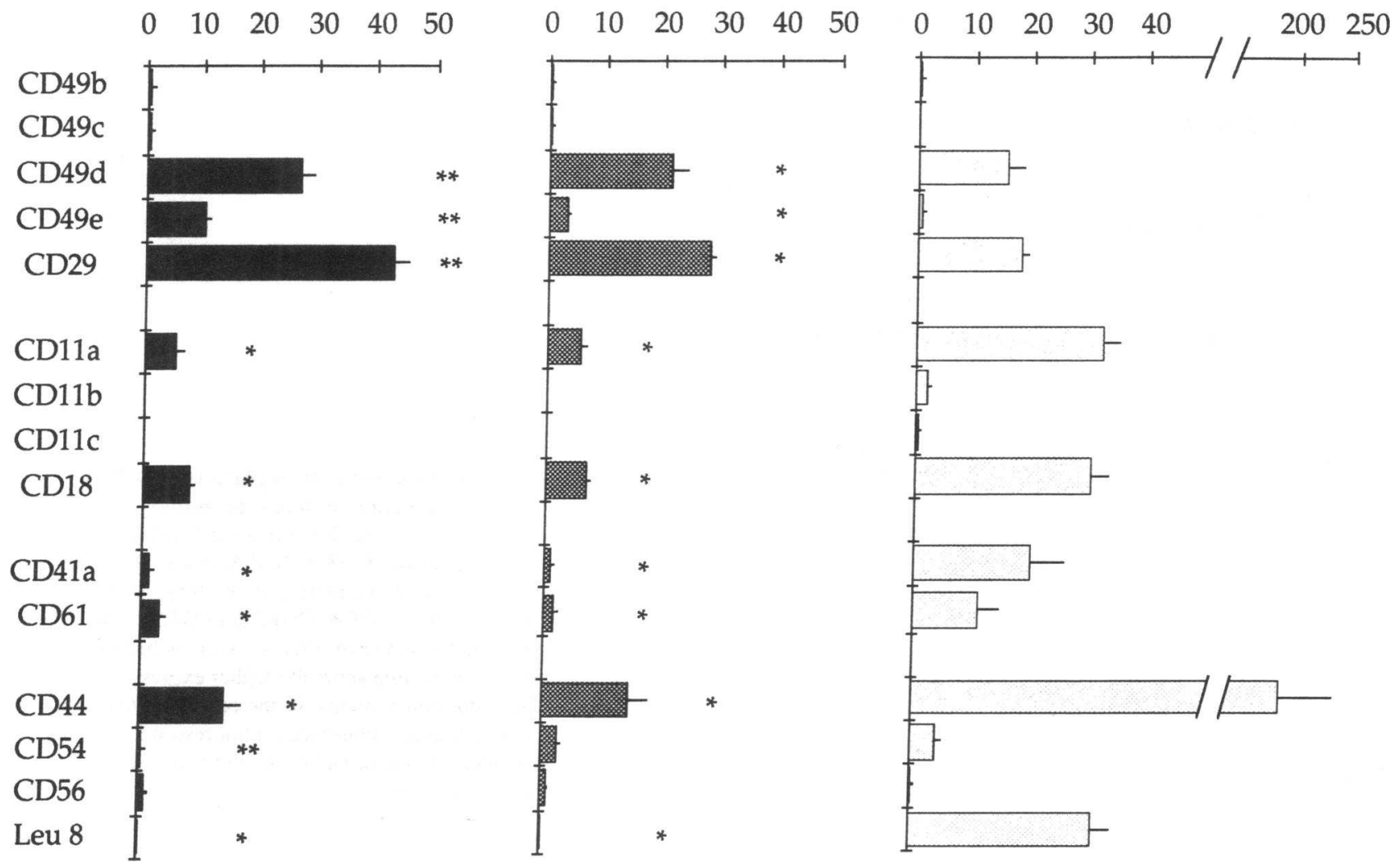

Figure 3. Adhesion protein phenotype of normal B lineage cells. The expression of adhesion proteins (determined as described above in Fig. 2) for early marrow B cell precursors (CD10 $0^{\text {hi }}$; left), late marrow B cell precursors (CD10 $0^{\text {lo }}$; middle), and mature peripheral blood B cells $\left(\mathrm{CD} 20^{+}\right.$; $r i g h t$ ) is indicated by the length of the bar (mean \pm SEM); $n=7-12$, except for CD49b, Leu 8, and CD11c [ $n=4]$ ). Single asterisks denote significant differences in fluorescence intensity between the $\mathrm{CD} 10^{+}$subpopulation indicated and mature blood $\mathrm{B}$ cells. Double asterisks denote significant differences in fluorescence intensity between the $\mathrm{CD} 10^{\text {hi }}$ cells and both $\mathrm{CD} 10^{\text {lo }}$ cells and mature blood $\mathrm{B}$ cells. Cell populations were unimodal, except for CD54 expression of CD10 $10^{\text {to }}$ cells and Leu 8 expression of peripheral blood B cells, in which a percentage of the population was entirely negative for the marker. It should be noted that the quantitation of fluorescence intensity is not equivalent to molecules of protein on the cell surface, since more than one antibody molecule can bind to each surface molecule, but reflects differences in expression of a given surface marker from one cell type to another.

Adhesion of NALM- 6 cells to BM-FB was significantly inhibited by CD29 (inhibition $57 \pm 12 \% ; n=3 ; P<0.05$ ) and CD49d (inhibition $52 \pm 10 \% ; n=3 ; P<0.05$ ), but was not inhibited by anti-fibronectin antibody or soluble FN-40. Adhesion of Reh cells to BM-FB was also blocked by CD49d (inhibition $90 \pm 1.3 \% ; n=3 ; P<0.001$ ), but not by anti-fibronectin antibody.

Identification of VCAM-1 on BM-FB. Based on the positive inhibition results with antibodies to VCAM-1 and the lack of inhibition with anti-fibronectin antibody or FN-40, evidence for expression of the alternative VLA-4 receptor, VCAM-1, on BM-FB was sought. Subconfluent BM-FB were VCAM-1 positive by immunofluorescence (Fig. 6), demonstrating varied intensity of expression. About $20 \%$ of cells showed bright staining, often focally concentrated along the cell membrane. These results, performed on unfixed BM-FB grown in situ on tissue culture chamber slides, were confirmed by flow cytometry analysis of trypsinized BM-FB stained with anti-VCAM-1, which showed significantly higher fluorescence relative to cells stained with irrelevant antibody. Furthermore, dermal fibroblasts, which do not preferentially bind B cell precursors, were negative for VCAM-1 expression by immunofluorescence microscopy.

BM-FB were negative for CD49d by immunofluorescence microscopy, and $\mathrm{CD} 10^{+}$bone marrow $\mathrm{B}$ cell precursors were negative for VCAM-1 by flow cytometry, indicating that VLA4 is expressed only by the B cell precursors and VCAM-1 only by the adherent cells in this system.

Effect of phorbol ester on adhesion of $B$ lineage cells to BM$F B$. PMA treatment increased binding of mature $B$ cells to a much greater degree than $\mathrm{CD} 10^{+} / \mathrm{CD}_{2} 0^{-}$cells, resulting in similar adherence of PMA treated precursor and mature $B$ lineage cells to BM-FB (Fig. 7 a). In a similar fashion, treatment with phorbol ester enhanced adhesion to BM-FB of mature B cell lines (7-29-6 and WIL-2) to a greater degree (3.7-fold increase) than B precursor cell lines (NALM-6 and Reh; 1.4-fold in- 


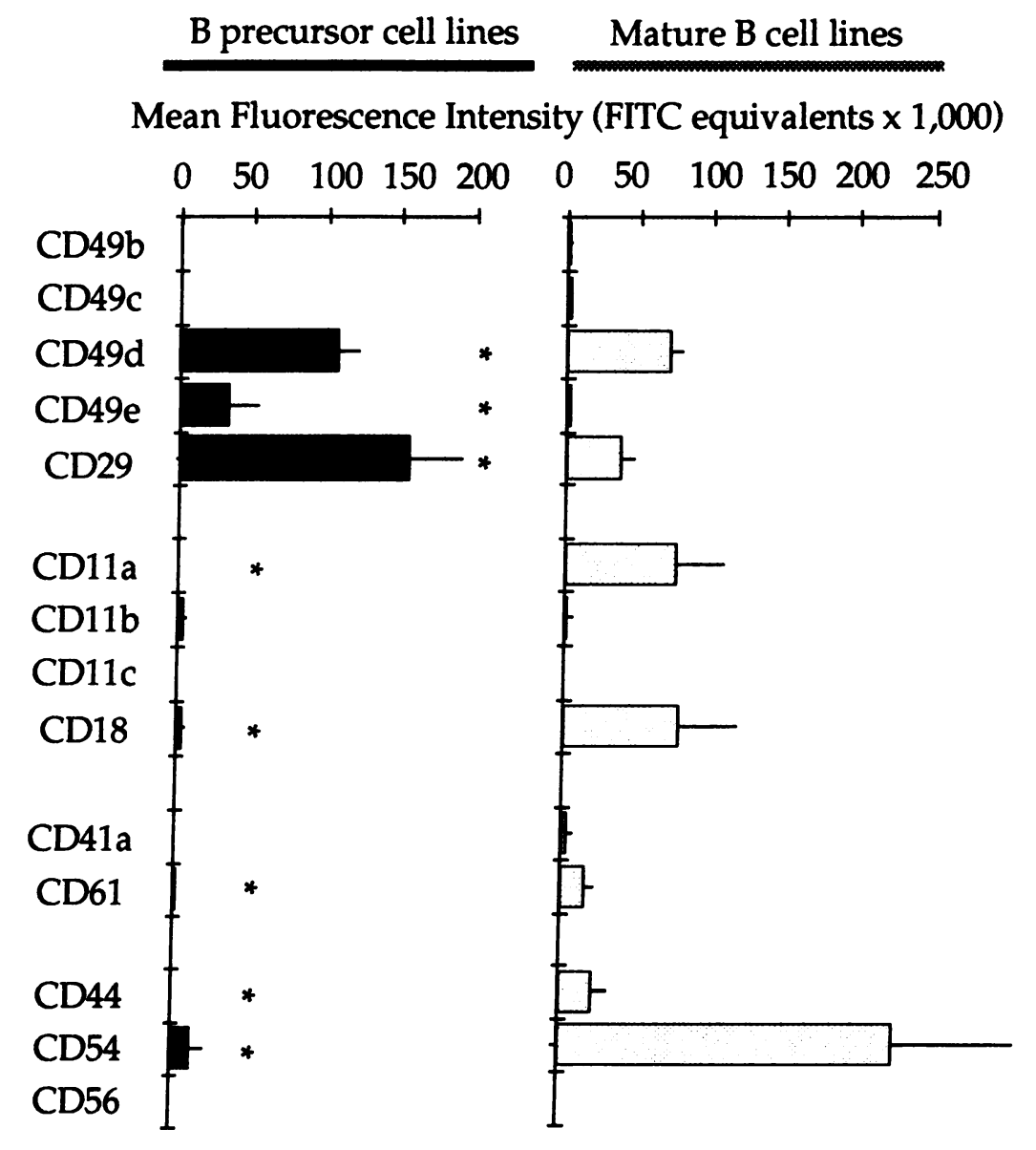

Figure 4. Adhesion protein phenotype of B lineage cell lines. Adhesion protein expression is shown as in Fig. 3. The value for precursor B cell lines represents the mean \pm SEM of NALM- 6 and Reh cells, while the value for mature $B$ cell lines represents the mean \pm SEM of 7-29-6, Daudi, and WIL-2 cells. Note that the fluorescence intensity scale is higher than in Fig. 3, indicating generally higher expression of surface adhesion proteins on the cell lines. Asterisks denote significant differences in fluorescence intensity between the mean values for the precursor and mature B cell lines. crease). The dependence of adherence on PMA concentration is similar in both mature B cells and B cell precursors, with significant increase in adherence at $0.16 \mathrm{nM}, \mathrm{PMA}$, and maximal adherence at 0.8-3.0 nM (data not shown).

Anti-CD29 inhibited binding of PMA-treated $\mathrm{CD} 10^{+} \mathrm{B}$ precursor cells to BM-FB, while anti-CD18 did not (Fig. 7, $\dot{b}$ and $c$ ). In contrast, binding of mature B cells to BM-FB in the presence of PMA was inhibited significantly by anti-CD18, but not anti-CD29. The presence of a CD18 counterreceptor, CD54 (ICAM-1), on BM-FB was confirmed by immunofluorescence microscopy.

\section{Discussion}

Although B cell precursors bind more avidly to BM-FB than do mature $B$ cells, many adhesion proteins increase in expression during early B cell development. We show here that two integrins, VLA-4 and VLA-5, are expressed at higher levels by B cell precursors than mature $B$ cells. The adhesion of $B$ cell precursors to BM-FB can be blocked by antibodies to VLA-4 and its counterreceptor VCAM-1, but not by antibodies to another VLA-4 ligand, fibronectin. VCAM-1 is expressed by BMFB, but not by dermal fibroblasts, which do not support adhesion of B precursor cells. These results indicate that VLA-4/ VCAM-1 interactions are necessary for the in vitro adhesion of human B cell precursors to a bone marrow-derived adherent cell population. Recent evidence indicates that VLA-4 medi- ates adhesion of murine $B$ cell precursors and is required for their development in long-term marrow culture (26). Our findings are also consistent with the recent description (27) of a 107-kD glycoprotein, possibly a murine VCAM-1 equivalent, on thymic stromal cells that mediates adhesion of a thymocyte cell line, and suggest the broad importance of VLA-4 and VCAM- 1 in mediating adhesion of mammalian lymphohematopoietic precursor cells.

Subpopulations of normal human bone marrow B cell precursors have been described based on expression of CD10, CD20, CD34, CD45, cytoplasmic Ig, and TdT. We (12) and others (28) have proposed a differentiation sequence of B lineage cells in which the order of CD10 and CD20 expression is: $\mathrm{CD} 10^{+} / \mathrm{CD} 20^{-}, \mathrm{CD} 10^{+} / \mathrm{CD} 20^{+}$, and $\mathrm{CD} 10^{-} / \mathrm{CD} 20^{+}$. We have previously observed that adhesion of subpopulations of normal B lineage cells to bone marrow derived fibroblasts decreases with increasing maturation (13).

In order to investigate the applicability of these observations to malignant human B cell precursors, B precursor leukemia cell lines were investigated. The cell lines NALM-6 and Reh demonstrated increased adhesion to BM-FB relative to dermal fibroblasts or fibronectin, and were more adherent to BM-FB than were mature B cell lines. These results are entirely consistent with the adhesion pattern of normal B cells (13).

Several adhesion proteins were expressed at higher levels in mature B cells than B cell precursors (CD44, LECAM1, LFA1, gp IIb/IIIa, CD54). The quantitative increase in LFA-1, CD44, and LECAM1 expression during B cell development 

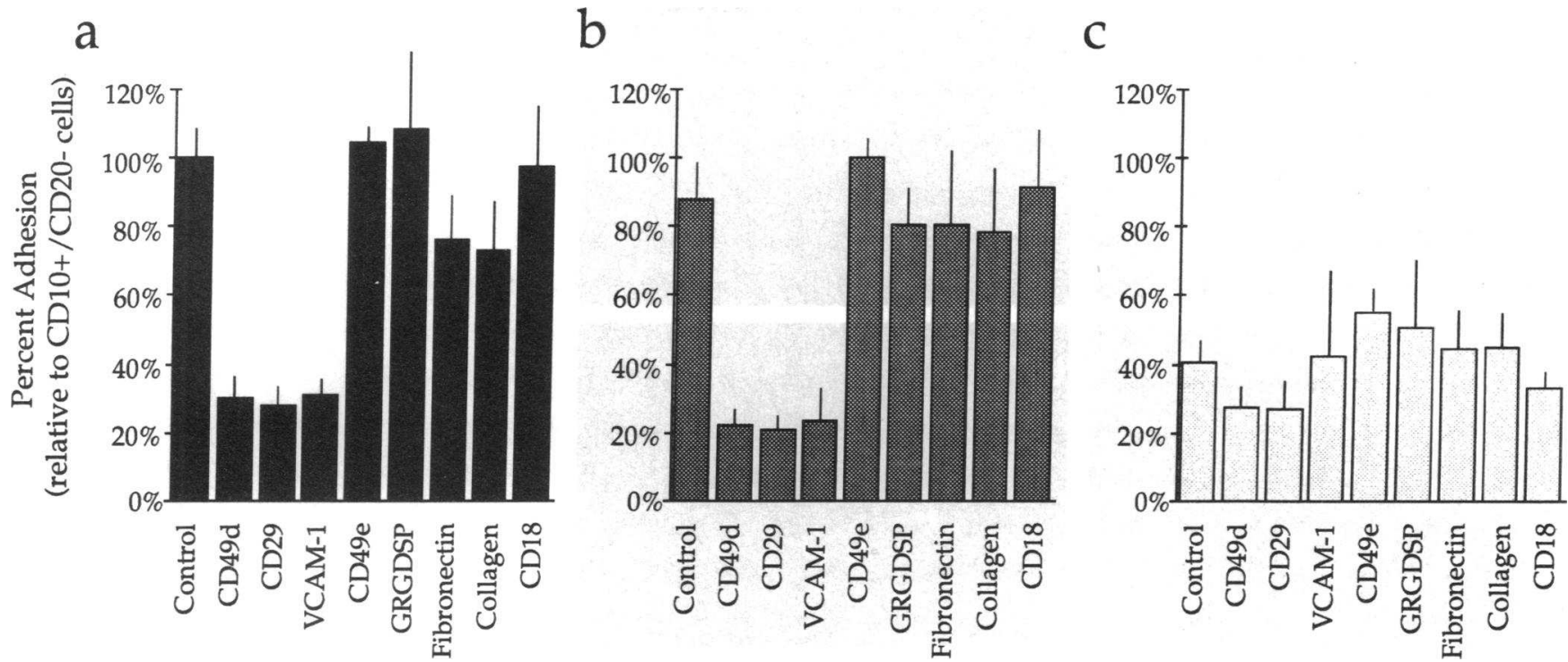

Figure 5. Blocking of adhesion of normal bone marrow B lineage cells to BM-FB. Data are presented separately for $(a) \mathrm{CD}^{+} 0^{+} / \mathrm{CD} 20^{-}$early B cell precursors, $(b) \mathrm{CD} 10^{+} / \mathrm{CD} 20^{+}$late $\mathrm{B}$ cell precursors, and $(c) \mathrm{CD} 10^{-} / \mathrm{CD} 20^{+}$mature $\mathrm{B}$ cells. The values shown represent the percent adherent cells relative to the percent adherent $\mathrm{CD} 10^{+} / \mathrm{CD}^{-} 0^{-}$cells in the control preparation (irrelevant antibody or GRGESP). Since these values represent the average of three to six separate experiments, each of which was performed in triplicate, the mean \pm SEM is shown. Using a paired $t$ test (comparing each blocking study with controls run at the same time), statistically significant inhibition of $\mathrm{CD} 10^{+} / \mathrm{CD}^{-} 0^{-}$cell adhesion was observed with CD49d $(P<0.0002), \mathrm{CD} 29(P<0.0005)$, and VCAM-1 $(P<0.002)$ antibodies. Significant inhibition of CD10 $0^{+} / \mathrm{CD} 20^{+}$cell adhesion was observed with CD49d $(P<0.005)$, CD29 $(P<0.002)$, and VCAM-1 $(P<0.05)$ antibodies. These differences remained highly significant in each case even if unpaired statistical analysis was used. None of the other antibodies resulted in statistically significant blocking of any cell subpopulation.

The binding assays were performed at $37^{\circ} \mathrm{C}$ since adhesion of B cell precursors to BM-FB was energy dependent. Binding of the most immature subset, $\mathrm{CD} 10^{+} / \mathrm{CD} 20^{-}$, was inhibited by $75 \%( \pm 4 \% ; n=4)$ from $47 \%$ to $12 \%$, whereas binding of mature $\mathrm{B}$ cells was inhibited by $50 \%$ $( \pm 3 \% ; n=4)$ from $18 \%$ to $9 \%$ if the adhesion assay was carried out at $4^{\circ} \mathrm{C}$ in the presence of $0.1 \%$ azide. Divalent cation-containing culture medium was used since adhesion of both mature and immature B cells to BM-FB was reduced by $>90 \%$ in culture medium with $0.15 \% \mathrm{~K}$ EDTA, and by $>95 \%$ in Hanks' medium with $0.6 \%$ albumin without $\mathrm{Ca}^{2+}$ or $\mathrm{Mg}^{2+}$. These findings are typical of integrin adhesion interactions (17).

that we observed is equivalent to that previously reported by Kansas and Dailey (16).

Of the adhesion proteins studied, only VLA-4 and VLA-5 were expressed at higher levels in $B$ cell precursors than in mature B cells. These changes in surface marker expression were not simply related to cell size, since B cell subpopulations show similar forward light scatter (12). In line with the data on normal B lineage cells, VLA-4 and VLA-5 are expressed more intensely by $B$ precursor lines than mature $B$ cell lines, whereas LFA-1, CD44, and CD54 are expressed more intensely by mature B cell lines.

VLA-4 and VLA-5 integrins are of interest since they are both fibronectin receptors, and murine $B$ cells show adhesion to fibronectin which diminishes during development (29). Murine $B$ cell precursors bind to fibronectin by two mechanisms (29), one involving the cell-binding domain of fibronectin, mediated by VLA- 5 and blocked by RGDS, and the other involving the IIICS (CS-1) heparin-binding domain of fibronectin, mediated by VLA- 4 and blocked by the peptide GPEILDVPST, not RGDS $(30,31)$.

Adhesion of normal B cell precursors and malignant B precursor cell lines to BM-FB was inhibited by blocking antibodies to either the $\alpha$ or $\beta$ chains of VLA-4, but not by blocking antibodies to the VLA-5 $\alpha$ chain or GRGDSP. The data therefore suggested that VLA-4, but not VLA-5, is required for adhesion in this system. The degree of blocking suggests that VLA-4 mediates the majority of the functional binding activity of $B$ cell precursors to BM-FB. The inhibition of adhesion caused by antibodies to either the $\alpha$ or $\beta$ chain of VLA- 4 was reproducible and statistically significant, even when the data were analyzed in an unpaired fashion.

There is precedent for involvement of VLA-4 in adhesion of human lymphohematopoietic cells. VLA-4 is expressed by mature B cells, T cells (32), NK cells (33), and macrophages. There is some evidence for a decrease in VLA-4 expression early in the $\mathrm{T}$ cell lineage, followed by an increase after activation of mature T cells (34). Functionally, VLA-4 mediates adhesion of mature germinal center B cells to dendritic cells in lymph node follicles (35), and is involved in adhesion and function of T cells and NK cells, as well as human erythroid progenitors (36).

VLA-4 has two known ligands, fibronectin and VCAM-1, a $100-\mathrm{kD}$ cytokine-induced endothelial adhesion protein that is a member of the immunoglobulin superfamily (37). VLA-4 is unique since it is the only member of the VLA family that has been reported to mediate cell-cell interactions (38). VCAM-1 interacts with VLA-4 at a site distinct from the fibronectin binding site (24).

Neither blocking antibodies to fibronectin nor a soluble fibronectin fragment (FN-40) containing the VLA-4 binding site inhibited $B$ precursor adhesion to BM-FB. The lack of inhibition by anti-fibronectin antibodies is not due to lack of fibronectin in the BM-FB layers, since BM-FB adherent layers contain abundant amounts of fibronectin by immunofluorescence 

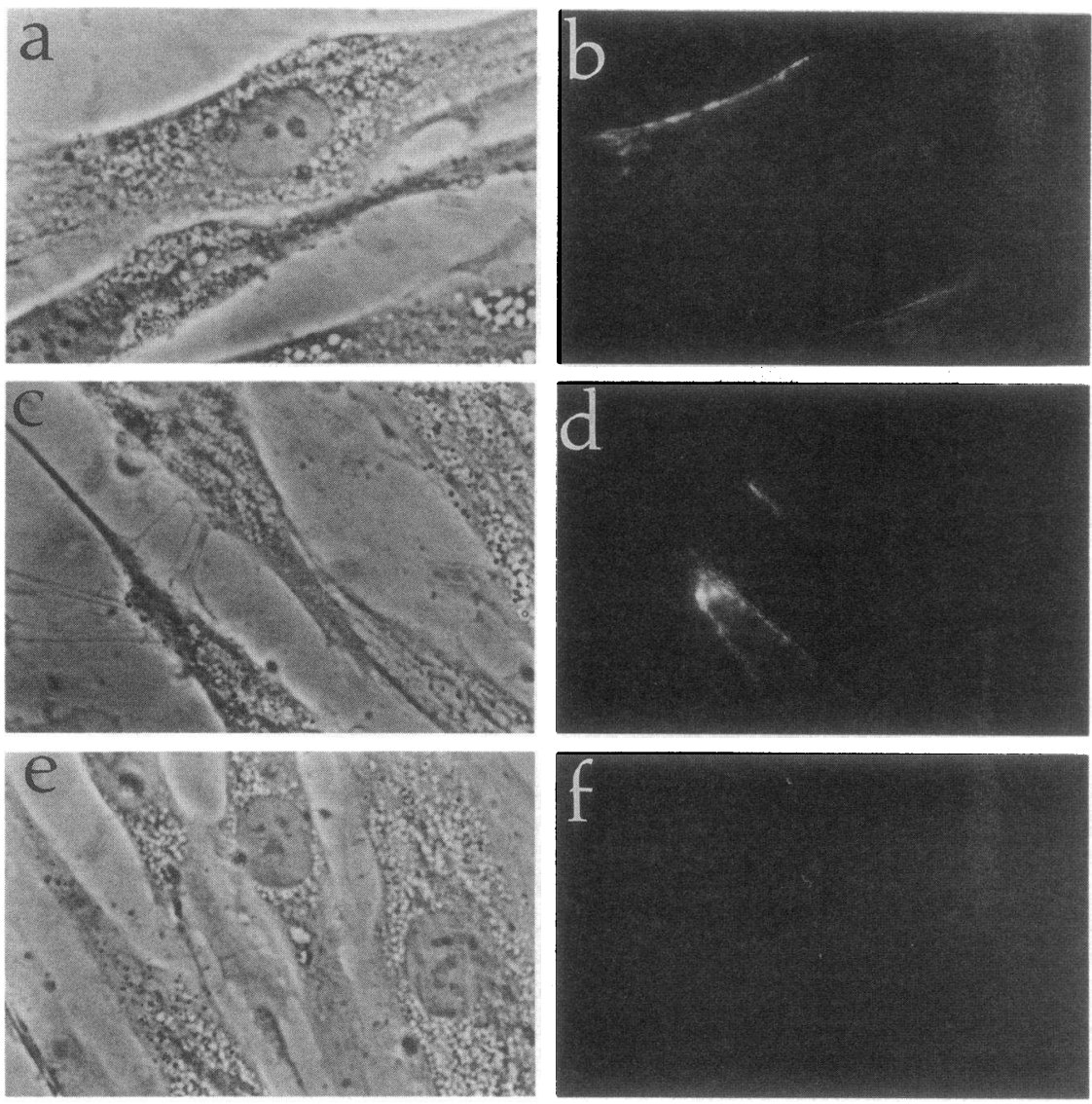

Figure 6. Immunofluorescence staining of BM-FB with anti-VCAM-1 antibody. Phasecontrast $(a, c$, and $e)$ and fluorescence $(b, d$, and $f$ ) photomicrographs of BM-FB cultured in eight-well culture chambers and stained with anti-VCAM-1 antibody $(b$ and $d)$ or irrelevant control antibody $(f)$, followed by FITC conjugated goat anti-mouse IgG. Note VCAM-1 positive and negative adherent cells in $b$ and $d$. staining (data not shown). Although B cell precursors express two potential fibronectin receptors (VLA-4 and VLA-5), these results suggest that fibronectin is not an important adhesion ligand for human B cell precursors. These results are confirmed by experiments on human B precursor cell lines, which show significant inhibition by CD29 and CD49d, but not anti-fibronectin or FN-40.

Antibodies to VCAM-1 blocked adherence of B precursor cells to BM-FB to a similar degree as CD49d antibodies, suggesting that VLA-4 is largely interacting with VCAM-1, and not fibronectin or an unidentified ligand. The identification of VCAM-1 as an adhesion receptor on BM-FB for B cell precursors is strengthened by the immunofluorescence and flow cytometry data indicating that BM-FB express VCAM-1. Dermal fibroblasts, which are morphologically similar to BM-FB but do not support adhesion of $B$ cell precursors, are negative for VCAM-1, again suggesting the importance of VCAM-1 in supporting adhesion of $B$ cell precursors. The antibody blocking studies do not identify which cells express VLA-4 and which express VCAM-1, since blocking antibody is in contact with both the $B$ cell precursors and BM-FB during the incubation. However, VCAM-1 is expressed by only BM-FB cells and not B cell precursors, and VLA-4 is expressed by only B cell precursors and not BM-FB, indicating that VLA-4 on the B cell precursor binds to VCAM-1 on the marrow-derived fibroblast layer.

VCAM-1 is primarily expressed by activated or inflamed endothelium (39), and not by resting or activated tissue fibroblasts (40). Therefore, the expression of this molecule by bone marrow-derived adherent cells which have the properties of fibroblasts (7) and have not been purposely activated was unex- pected. Recent data indicates that VCAM-1 may be expressed by a wider range of normal cells than previously appreciated (22).

Since VLA-4 is a functional adhesion receptor on B cell precursors as well as mature germinal center B cells and memory $\mathrm{T}$ cells, its expression may not be the sole explanation for the different tissue localization of $B$ cell precursors and circulating VLA-4-positive lymphoid cells. Specificity of tissue homing may result from regulation of VLA-4 affinity (41) or involvement of additional adhesion receptors in a cascade of adhesion receptor activation, as has been observed with CD44 and LFA-1 (42).

One way in which the affinity of adhesion receptors can be regulated is by protein kinase $\mathrm{C}$ activation, as described for LFA-1. In our system, blocking studies do not suggest an important role for LFA-1 in adhesion of resting B cells to BM-FB. After treatment with phorbol esters, however, the adhesion of mature B cells increased, and was partially inhibitable by blocking antibodies to LFA-1. Interestingly, the up-regulated adhesion of phorbol-treated B cell precursors was blocked partially by antibodies to VLA-4 and not LFA-1. There is precedent for up-regulation of VLA-4 affinity by phorbol esters in T cells (41), although the possibility of phorbol up-regulation of VCAM-1 affinity should be considered, since both the B cell precursors and the BM-FB are exposed to PMA in this system. BM-FB express both VCAM-1 and ICAM-1, and hence can support VLA-4- or LFA-1-mediated adhesion. These results suggest that a single mechanism of $B$ cell activation may result in upregulated adhesion to different substrates, depending on the stage of differentiation of the B cell.

It is possible that the nonrandom bone marrow distribution 

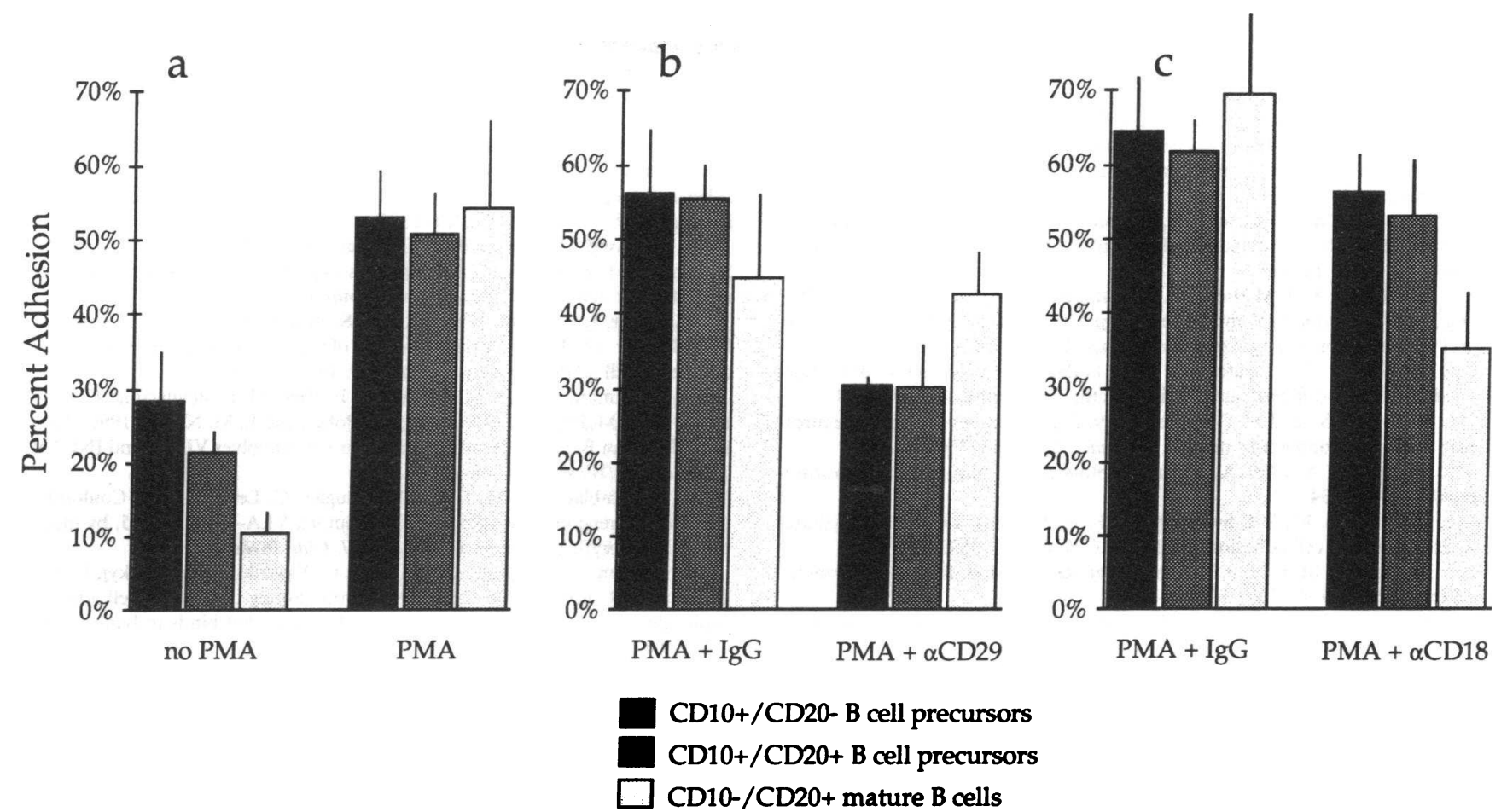

Figure 7. Effect of phorbol ester on B cell adhesion to BM-FB (mean percent adhesion \pm SEM). (a) Effect of PMA on adhesion of normal bone marrow B cell subpopulations to BM-FB ( $n=4$; each experiment performed in triplicate). There is a significant increase in adhesion of each $B$ lineage population, but the magnitude of the increase is greatest in mature $\mathrm{CD} 10^{-} / \mathrm{CD} 20^{+} \mathrm{B}$ cells, resulting in similar adherence of PMA-treated precursor and mature B lineage cells to BM-FB. Controls were treated with $0.1 \%$ ethanol. $(b)$ Effect of CD29 antibody on adherence of PMAtreated normal B cell subpopulations to BM-FB. The controls for these experiments $(n=3)$ were treated with PMA plus irrelevant monoclonal antibody. Using a paired $t$ test (comparing each blocking study with controls run at the same time), CD29 significantly blocked adhesion of $\mathrm{CD} 10^{+} / \mathrm{CD}^{-} 0^{-}(P<0.05)$ and $\mathrm{CD} 10^{+} / \mathrm{CD}^{+} 0^{+}(P<0.01)$ cells. These differences remained significant in each case even if unpaired statistical analysis was used. (c) Effect of CD18 on adherence of PMA-treated normal B cell subpopulations to BM-FB. These experiments $(n=5)$ were performed as described above. Using a paired $t$ test, the inhibition of $\mathrm{CD} 10^{-} / \mathrm{CD} 20^{+}$mature B cells was statistically significant $(P=0.05)$.

of B lymphocyte precursors (43) may be due to localized VCAM-1 expression in the marrow. Adhesion of human myeloid progenitors to bone marrow stroma is not inhibited by anti-VLA-4 antibodies (44), suggesting differences in adhesion specificity between lymphoid and myeloid progenitors which may be responsible for different tissue localization of these cells within the bone marrow cavity (45).

The functional significance of VLA-4/VCAM-1 interactions in human B lymphopoiesis is not yet known, although studies in the murine long-term lymphoid culture system (26) suggest that VLA-4 interactions are necessary in B cell development. Fetal human $B$ cell precursors may be capable of in vitro proliferation in the presence of IL-7 and adherent cells grown from adult human bone marrow (46). This suggests that the bone marrow-derived adherent cells in our system may be capable of providing a genuine microenvironment for B cell lymphopoiesis under the proper culture conditions, permitting investigation of the role of VLA- 4 and VCAM- 1 mediated adhesion in lymphopoiesis.

\section{Acknowledgments}

We acknowledge the skilled technical assistance of Ms. Nancy Halstead and Mr. Steve Mitchell.

This investigation was supported by Biomedical Research Support Grant S7RR05403-27, U.S. Public Health Service grant PO1
HL18208-15, awarded by the National Cancer Institute, and U. S. Public Health Service training grant HL-07152.

\section{References}

1. Whitlock, C. A., and O. N. Witte. 1982. Long-term culture of B lymphocytes and their precursors from murine bone marrow. Proc. Natl. Acad. Sci. USA. 79:3608-3612.

2. Dorshkind, K., L. Schouest, and W. H. Fletcher. 1985. Morphologic analysis of long-term bone marrow cultures that support B-lymphopoiesis or myelopoiesis. Cell Tissue Res. 239:375-382.

3. Medlock, E., I. Goldschneider, D. Greiner, and L. Shultz. 1987. Defective lymphopoiesis in the bone marrow of motheaten $(\mathrm{me} / \mathrm{me})$ and viable motheaten (mev/mev) mutant mice. II. Description of a microenvironmental defect for the generation of TdT positive bone marrow cells in vitro. J. Immunol. 138:35903597.

4. Kierney, P. C., and K. Dorshkind. 1987. B lymphocyte precursors and myeloid progenitors survive in diffusion chamber cultures but $B$ cell differentiation requires close association with stromal cells. Blood. 70:1418-1424.

5. Jacobsen, K., and D. G. Osmond. 1990. Microenvironmental organization and stromal cell associations of B lymphocyte precursor cells in mouse bone marrow. Eur. J. Immunol. 20:2395-2404.

6. Tsai, S., C. A. Sieff, and D. G. Nathan. 1986. Stromal cell-associated erythropoiesis. Blood. 67:1418-1426.

7. Liesveld, J. L., R. Duerst, D. H. Ryan, J. Brennan, C. N. Abboud, and M. A. Lichtman. 1989. Characterization of human marrow stromal cells: role in progenitor cell binding and granulopoiesis. Blood. 73:1794-1800.

8. Dexter, T. M., T. C. Allen, and L. G. Lajtha. 1977. Conditions controlling the proliferation of haematopoietic stem cells in vitro. J. Cell. Physiol. 91:335344.

9. Flanagan, J. G., D. C. Chan, and P. Leder. 1991. Transmembrane form of the kit ligand growth factor is determined by alternative splicing and is missing in the $S l^{d}$ mutant. Cell. 64:1025-1035. 
10. LeBien, T. W. 1989. Growing human B-cell precursors in vitro: the continuing challenge. Immunol. Today. 10:296-298.

11. Uckun, F. M. 1990. Regulation of human B-cell ontogeny. Blood. 76:1908-1923.

12. Ryan, D., S. Kossover, S. Mitchell, C. Frantz, L. Hennessy, and H. Cohen. 1986. Subpopulations of common acute lymphoblastic leukemia antigen-positive lymphoid cells in normal bone marrow identified by hematopoietic differentiation antigens. Blood. 68:417-425.

13. Ryan D. H., B. L. Nuccie, C. N. Abboud, and J. L. Liesveld. 1990. Maturation-dependent adhesion of human B cell precursors to the bone marrow microenvironment. J. Immunol. 145:477-484.

14. Miyake, K., K. J. Medina, S-I. Hayashi, S. Ono, T. Hamaoka, and P. W. Kincade. 1990. Monoclonal antibodies to Pgp-1/CD44 block lympho-hemopoiesis in long-term bone marrow cultures. J. Exp. Med. 171:477-488.

15. Bernardi, P., V. P. Patel, and H. F. Lodish. 1987. Lymphoid precursor cells adhere to two different sites on fibronectin. J. Cell Biol. 105:489-498.

16. Kansas, G. S., and M. O. Dailey. 1989. Expression of adhesion structures during B cell development in man. J. Immunol. 142:3058-3062.

17. Springer, T. A. 1990. Adhesion receptors of the immune system. Nature (Lond.) 346:425-434.

18. Brandley, B. K., S. J. Swiedler, and P. W. Robbins. 1990. Carbohydrate ligands of the LEC cell adhesion molecules. Cell. 63:861-863.

19. Humphries, M. J. 1990. The molecular basis and specificity of integrin-ligand interactions. J. Cell Sci. 97:585-592.

20. Levy, J. A., M. Virolainen, and V. Defendi. 1968. Human lymphoblastoid lines from lymph node and spleen. Cancer. 22:517-524.

21. Brown, D. L., D. R. Phillips, C. H. Damsky, and I. F. Charo. 1989. Synthesis and expression of the fibroblast fibronectin receptor in human monocytes. J. Cell Biol. 84:366-370.

22. Rice, G. E., J. M. Munro, C. Corless, and M. P. Bevilacqua. 1991. Vascular and nonvascular expression of INCAM-110. Am. J. Pathol. 138:385-393.

23. Tedder, T. F., M. D. Cooper, and L. T. Clement. 1985. Human lympho cyte differentiation antigens HB-10 and HB-11. II. Differential production of B cell growth and differentiation factors by distinct helper $\mathrm{T}$ cell subpopulations. $J$. Immunol. 134:2989-2994.

24. Elices, M. J., L. Osborn, Y. Takada, C. Crouse, S. Luhowskyj, M. E Hemler, and R. R. Lobb. 1990. VCAM-1 on activated endothelium interacts with the leukocyte integrin VLA-4 at a site distinct from the VLA-4/fibronectin binding site. Cell. 60:577-584.

25. Rice, G. E., J. M. Munro, and M. P. Bevilacqua. 1990. Inducible cell adhesion molecule 110 (INCAM-1 10) is an endothelial receptor for lymphocytes. J. Exp. Med. 171:1369-1374.

26. Miyake, K., I. L. Weissman, J. S. Greenberger, and P. W. Kincade. 1991. Evidence for a role of the integrin VLA-4 in lympho-hemopoiesis. J. Exp. Med. 173:599-607

27. Kina, T., A. S. Majumdar, S. Heimfeld, H. Kaneshima, B. Holzmann, Y. Katsura, and I. L. Weissman. 1991. Identification of a 107-kD glycoprotein that mediates adhesion between stromal cells and hematolymphoid cells. J. Exp. Med. 173:373-381.

28. Loken, M. R, V. O. Shah, K. L. Dattilio, and C. I Civin 1987. Flow cytometric analysis of human bone marrow. II. Normal B lymphocyte development. Blood. 70:1316-1324.

29. Bernardi, P., V. P. Patel, and H. F. Lodish. 1987. Lymphoid precursor cells adhere to two different sites on fibronectin. J. Cell Biol. 105:489-498.

30. Garcia-Pardo, A., E. A. Wayner, W. G. Carter, and O. C. Ferreira. 1990.
Human B lymphocytes define an alternative mechanism of adhesion to fibronectin. J. Immunol. 144:3361-3366.

31. Guan, J.-L., and R. O. Hynes. 1990. Lymphoid cells recognize an alternatively spliced segment of fibronectin via the integrin receptor $\alpha_{4} \beta_{1}$. Cell. 60:5361.

32. Wayner, E. A., A. Garcia-Pardo, M. J. Humphries, J. A. McDonald, and W. G. Carter. 1989. Identification and characterization of the T lymphocyte adhesion receptor for an alternative cell attachment domain (CS-1) in plasma fibronectin. J. Cell Biol. 109:1321-1330.

33. Gismondi, A., S. Morrone, M. J. Humphries, M. Piccoli, L. Frati, and A. Santoni. 1991. Human natural killer cells express VLA-4 and VLA-5, which mediate their adhesion to fibronectin. J. Immunol. 146:384-392.

34. Picker, L. J., L. W. Terstappen, L. S. Rott, P. R. Streeter, H. Stein, and E. C. Butcher. 1990. Differential expression of homing-associated adhesion molecules by $T$ cell subsets in man. J. Immunol. 145:3247-3255.

35. Freedman, A. S., J. M. Munro, G. E. Rice, M. P. Bevilacqua, C. Morimoto, B. W. McIntyre, K. Rhynhart, J. S. Pober, and L. M. Nadler. 1990. Adhesion of human B cells to germinal centers in vitro involves VLA-4 and INCAM110. Science (Wash. DC). 249:1030-1033.

36. Rosemblatt, M., M. H. Vuillet-Gaugler, C. Leroy, and L. Coulombel. 1990. Coexpression of two fibronectin receptors, VLA-4 and VLA-5, by immature human erythroblastic precursor cells. J. Clin. Invest. 87:6-11.

37. Osborn, L., C. Hession, R. Tizard, C. Vassallo, S. Luhowskyj, G. ChiRosso, and R. Lobb. 1989. Direct expression cloning of vascular cell adhesion molecule 1 , a cytokine-induced endothelial protein that binds to lymphocytes. Cell. 59:1203-1211.

38. Campanero, M. R., R. Pulido, M. Ursa, M. Rodriguez-Moya, M. O. de Landazuri, and F. Sanchez-Madrid. 1990. An alternative leukocyte homotypic adhesion mechanism, LFA-1/ICAM-1-independent, triggered through the human VLA-4 integrin. J. Cell Biol. 110:2157-2165.

39. Rice, G. E., and M. P. Bevilacqua. 1989. An inducible endothelial cell surface glycoprotein mediates melanoma adhesion. Science (Wash. DC) 246:1303-1306.

40. Carlos, T. M., B. R. Schwartz, N. L. Kovach, E. Yee, M. Rosso, L. Osborn, G. Chi-Rosso, B. Newman, R. Lobb, and J. M. Harlan. 1990. Vascular cell adhesion molecule-1 mediates lymphocyte adherence to cytokine-activated cultured human endothelial cells. Blood. 76:965-970.

41. Shimizu, Y., G. A. Van Seventer, K. J. Horgan, and S. Shaw. 1990. Regulated expression and binding of three VLA $(\beta 1)$ integrin receptors on T cells. Nature (Lond.). 345:250-253.

42. Koopman, G., Y. van Kooyk, M. de Graaff, C. J. L. M. Meyer, C. G. Figdor, and S. T. Pals. 1990. Triggering of the CD44 antigen on T lymphocytes promotes T cell adhesion through the LFA-1 pathway. J. Immunol. 145:35893593.

43. Jacobsen, K., J. Tepper, and D. G. Osmond. 1990. Early B-lymphocyte precursor cells in mouse bone marrow: subosteal localization of $\mathrm{B220}+$ cells during postirradiation regeneration. Exp. Hematol. 18:304-310.

44. Winslow, J. M., J. L. Liesveld, K. E. Frediani, D. H. Ryan, and C. N. Abboud. 1990. Integrin expression and role in adhesion of normal and leukemic hematopoietic cells. Blood. 76:127a. (Abstr.)

45. Lord, B. I. 1990. The architecture of bone marrow cell populations. Int. J. Cell Cloning. 8:317-331

46. Wolf, M. L., J. A. Buckley, and T. W. LeBien. 1990. Human recombinant IL-7 induces proliferation of normal human B-cell precursors. Blood. 76:224a. (Abstr.) 